tribution is used. A glance at this table shows immediately that certain investigations are linked with geographical regions; for example, glaciological investigations are particularly concentrated in the arctic and antarctic regions. In the other regions, observations are dependent on the presence of glaciers. From another point of view, observations of an astronomical character such as longitudes and latitudes, or even solar observations, are essentially based on the existing observatories. These tend to be concentrated in the northern hemisphere in the region of the middle latitudes.

However, it is impossible to regard all stations as being of equal importance, because within each discipline there are profound differences in the type of observations. In meteorology, for example; an aerological station will make at least radiosonde observations, while a radiation station need only have simple apparatus for measuring the total radiation, and the results obtained may not be very accurate. On the other hand, rockets, which numerically make the smallest contribution to the International Geophysical Year programme, represent an effort so much in excess of their numbers that only four National Committees, namely, Japan, the United Kingdom, the United States and the U.S.S.R., have been able to participate. The U.S.S.R. rocket and Earth satellite programme was presented to the Bureau of the Comité Spécial de l'Année Géophysique Internationale on June 16, 1957. A total of 125 rockets will be launched; of these, 25 will be fired in the Arctic, from Franz Joseph Land, 70 from the middle latitudes of the Soviet Union, and 30 from the region around Mirny in the Antarctic. The firings will be made at approximately regular intervals, mainly on World Days and Special World Days.

It may be interesting to point out how the observations being undertaken in one of the dis. ciplines are subdivided. Observations of auroras can be visual, photographic, spectrophotometric, spectrographic or radioelectric, and the various techniques are essentially different. There will probably be more than two hundred stations observing auroras visually, to which can be added other observations made by meteorological stations and by amateur astronomers. In addition, there will be 104 all-sky cameras, which will make possible a continuous photographic record of auroras so far as clear skies allow, and of these fifty-nine will be in the Arctic region. The number of spectrographs will be about thirty-six, of which fifteen will be in the Arctic and nine in the Antarctic.

It is impossible to write in detail about the many subjects under investigation when giving an impression of the contribution of each National Committee organizing observations during the International Geophysical Year. However, geomagnetism may be taken as a typical example. Table 3 gives the schedule prepared for certain regions by various National Committees. There will be, according to this programme-which is, of course, an essential part of the Year's programme-178 geomagnetic stations registering the three components, $D, H$ and $Z$. With regard to the numbers given in column $a$, these are not very significant, because the number of stations based on a portable instrument is practically unlimited.

Among the most remarkable efforts to be undertaken during the International Geophysical Year, the observations to be made in the polar regions are probably the most spectacular. The stations and observations that will be carried out in the Arctic are given in Table 4, and those in the Antarctic in Table 5.

This outline of the projected activities of the International Geophysical Year, though lacking in detailed description, nevertheless indicates a scientific reality of great magnitude. The whole object is to integrate a series of observations which require international co-operation on a scale never before realized. This has been achieved by a number of round-table talks, in which some of the world's leading astronomers, geophysicists, meteorologists and others have proposed, discussed and then agreed on suitable programmes. Finally-and this is the most importantit shows that a practical solution to the problems of modern science can only be found by mutual contributions to the task, as is illustrated so well by the efforts of the National Committees contributing to the International Geophysical Year.

\title{
GEOPHYSICAL INVESTIGATIONS ON THE FLOOR OF THE ATLANTIC OCEAN IN DISCOVERY II, 1956
}

\begin{abstract}
A DISCUSSION meeting concerning the geophysical investigations made in the Atlantic from R.R.S. Discovery II in 1956 was held in the rooms of the Royal Society on May 2. Sir Cyril Hinshelwood, president of the Royal Society, was in the chair and the meeting was introduced by Sir Edward Bullard. He described the track (Fig. 1) of Discovery $I I$ on the cruise and the type of investigation which was made. While the ship was on passage continuous echo-sounding profiles and total force magnetic measurements were obtained. The station work consisted of seismic refraction shooting experiments, measurements of the heat flow through the ocean floor, coring, dredging, bottom photography and detailed magnetic and topographic surveys in a few limited areas. In addition to this, one measurement was made of the deep current at a depth of $3,000 \mathrm{~m}$.
\end{abstract}

The scientific personnel on the expedition consisted of Mr. R. D. Adams, Sir Edward Bullard, Mr. J. C. Cleverly and Dr. M. N. Hill from the Department of Geodesy and Geophysics at Cambridge, Dr. R. G. Mason and Mr. F. Gray from the Imperial College of Science and Technology, Dr. A. S. Laughton and Dr. J. C. Swallow from the National Institute of Oceanography, and Prof. R. W. Raitt of the Scripps Institution of Oceanography in California, and Dr. T. F. Gaskell of British Petroleum Co., Ltd. The last two were each present for half the cruise.

An important new technique was used on the detailed surveys; this consisted of the mooring of dan buoys with radar reflectors on them in deep water. This allowed a better control of position to be obtained than is possible with astronomical sights alone. The new types of investigation used on the expedition were the photography of the sea-bed with 


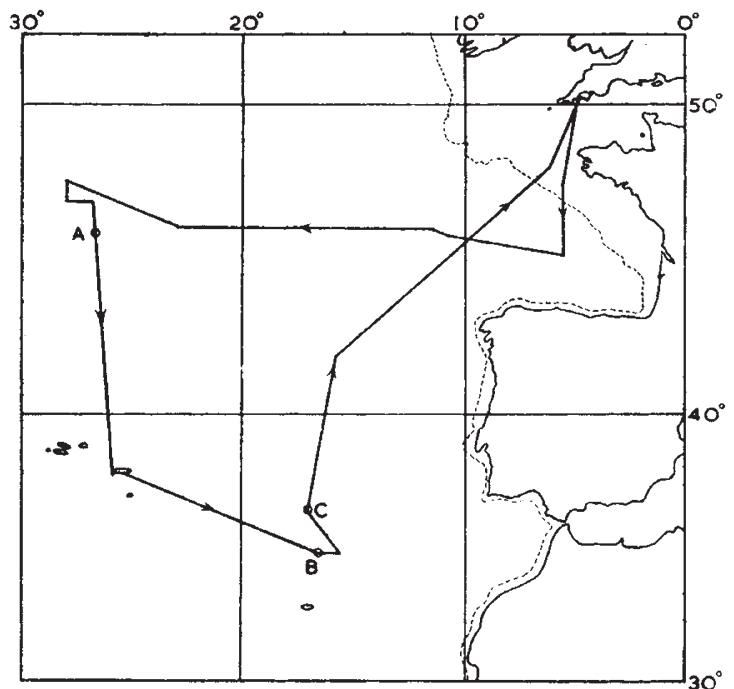

Fig. 1. Track of Discovery II during July and August 1956. Points $A, B$ and $C$ show where buoys were moored

Dr. A. S. Laughton's camera and the measurement of the Earth's total magnetic field with a towed nuclear-spin magnetometer.

Sir Edward completed his introductory remarks by acknowledging his gratitude to Dr. G. E. R. Deacon, director of the National Institute of Oceanography, for providing six weeks of Discovery II's time for these investigations.

Dr. M. N. Hill gave a brief deseription of the topography of the area of the Atlantic in which the recent investigations and those of earlier expeditions have been made. 'The area can be sub-divided into four different types of topographic terrains. First, to the north there is the extensive, comparatively shallow smooth area lying to the west of Scotland and extending to Iceland and Greenland. Secondly, there are the abyssal plains lying close to the foot of the continental shelf at depths of about 2,500-2,900 fathoms ; these plains are isolated from one another by ridges and are generally flat to within a fow parts in ten thousand and stretch out to a distance of approximately two to three hundred miles from the foot of the continental slope. 'The third type of topography lies to the west of the abyssal plains; it is shallower and consists of gently sloping areas with seamounts and ridges sticking up through the sedimentary cover. In width this third type is again about two to three hundred rniles. Farther to the west, and centred about the line of $30^{\circ} \mathrm{W}$. longitude, lies the Mid-Atlantic Ridge where the bottom topography is precipitous, with no extensive flat or smooth areas. The Ridge width is variable but is again in the neighbourhood of 300 miles. 'Tho minimum depth to the higher peaks of the Ridge is about 600 fathoms and the mean level in the middle about 1,300 fathoms.

In the middle of the Ridge and roughly following its axis there is a deep valley approximately $1,800-$ 2,200 fathoms in depth. The floor of the valley is about five miles across, and between the tops of the ridges forming its sides the width is about 10 miles. This valley was discovered in cruises of H.M.S. Challenger by Dr. Swallow in 1953 and since then some detailed surveys have been made of restricted parts of it. Its length is at least 85 miles and it seerns to be blocked at its southern end in about latitude $47^{\circ} 20^{\prime} \mathrm{N}$. 'To the north its limit is not known. In the 1956 expedition the investigations were undertaken near its southern limit. Prof. M. Ewing has suggested that this valley exists with occasional breaks in it throughout the length of the Ridge from $55^{\circ} \mathrm{N}$. lat. down to the latitude of Cape 'Town and that it there swings to the east and continues up the ridges in the western Indian Ocean. There is some support for this suggestion in the limited sounding information available, but its continuity is open to much doubt.

Dr. A. S. Laughton was the next speaker and he described the method of photography of the sea-bed which he has developed. The camera and flash tube are mounted on a framework of scaffold tubing and are arranged with the camera sufficiently far above the light source to allow for photographing of the shadows behind smaller objects lying on the sea-bed. The camera is operated by a weight hanging about I0 $\mathrm{ft}$. below it. When this weight touches the sea. bed it triggers the flash and operates switches, one of which winds the film and another transmits a sound pulse back to the surface. 'This sound is a signal for the camera to be lifted clear of the bottom. Because of the drifting of the ship, subsequent lowerings will photograph different areas of the sea floor ; up to one hundred photographs can be obtained before the camera need be brought back to the surface.

This camera was used at numerous positions during the cruise at depths between about 60 fathoms and 2,650 fathoms, and in all two hundred black-andwhite photographs were obtained.

The most interesting series of photographs were those obtained from a seamount (Position $B$ on Fig. 1) at the south-eastern corner of the track which was surveyed in detail. 'These demonstrated the existence of loose boulders on the sea-bed near the top of the seamount, outcrops of rock and pockets of sediments on the flanks (Fig. 2). In the deeper water there are oceanic sediments which, as was usually found elsewhere, are covered with numerous indications of the existence of bottom fauna. These photographs were all of great interest in relation to the rocks obtained by dredging in the area and to the topography obtained by the echo-sounder.

Mr. R. D. Adams, of the Department of Geodesy and Geophysies at Cambridge, who was to a large extent responsible for the seismic refraction shooting experiments undertaken during the cruise, described the seismological investigations he had made before and after the cruise. These were related to the refraction shooting results, since, by studying the Rayleigh and Love waves from earthquakes in the Mid-Atlantic Ridge, it was possible to learn some details of the average crustal structure below the Atlantic Ocean. 'The earthquake epicentres of the Ridge lie along the axis and exist throughout the length of the Ridge. Adams discussed the results from earthquakes from the northern part of the Ridge picked up at Kew and on the long-period seismographs at Cambridge.

It has previously been suggested by Prof. J. P. Rothe that on the eastern side of the Ridge the crustal structure is nearer that of the continents than on the western side and in other oceanic areas. 'This is not substantiated by the dispersion results obtained by Adams, which showed that, after the effects of the continental part of the track had been removed from the observations, the results were indistinguishable from those obtained from other oceanic areas. 


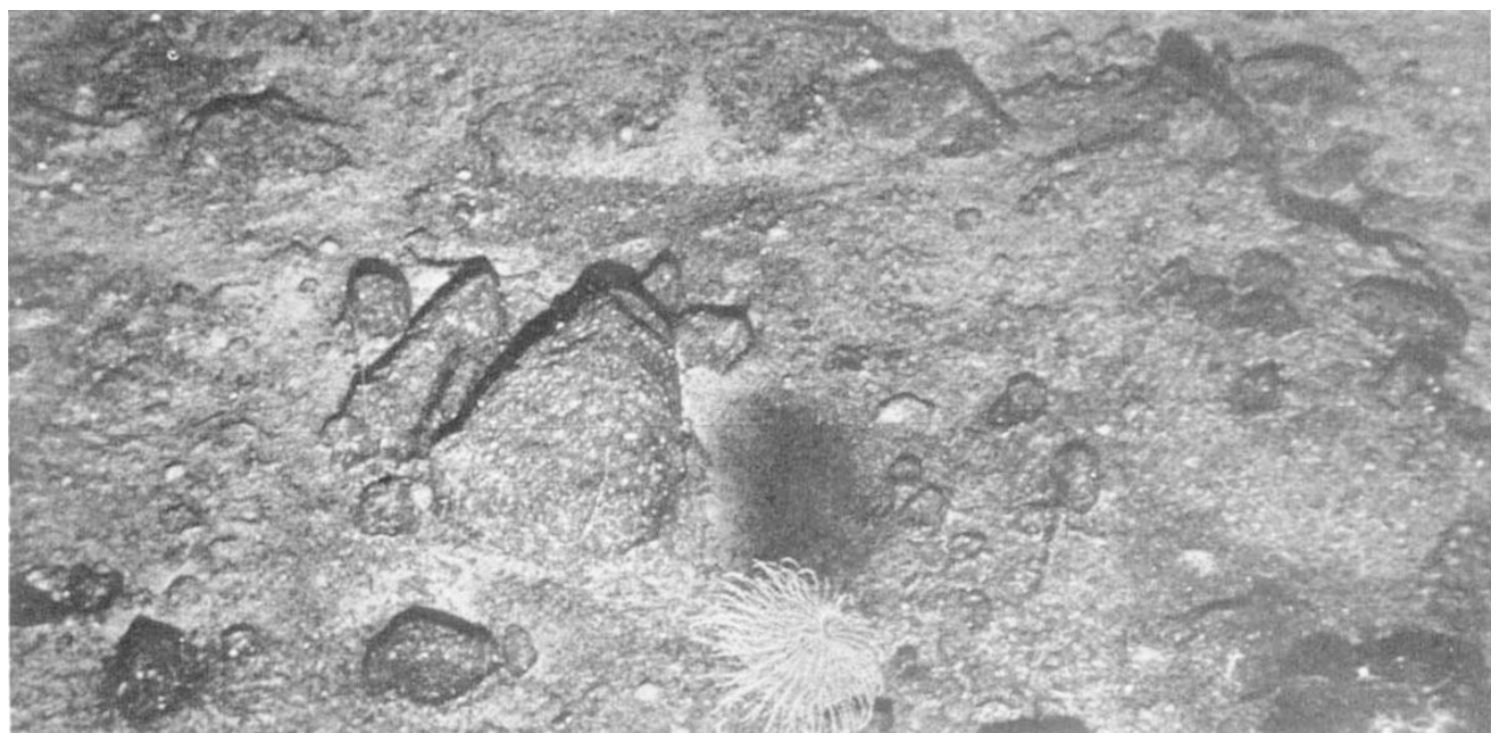

Fig. 2. Loose boulders and some outcropping bedrock near the peak of a volcanic seamount north of Madeira. In the foreground is a spiralling Gorgonid. The depth of water was 800 fathoms

This conclusion agreed with the seismic refraction shooting results. Adams pointed out that interesting results concerning the Mid-Atlantic Ridge structure might be obtained from the installation of longer period seismographs in the Azores than those at present in use; the surface waves were not at present being recorded.

Dr. M. N. Hill gave a brief summary of the seismic refraction shooting results obtained from those areas, largely in the Atlantic and Pacific oceans, in which this type of measurement has been made and compared them with those obtained in the north-eastern Atlantic. The top layer (Layer 1) consists of unconsolidated sediments (compressional wave velocity $2 \mathrm{~km}$./ sec.) which in water depths greater than about 2,000 fathoms has an average thickness of approximately $350 \mathrm{~m}$. 'This overlies a layer in which the velocity of eompressional waves lies between 4 and $6 \mathrm{~km}$. $/ \mathrm{sec}$. and which has a mean thickness of about $1 \cdot 6 \mathrm{~km}$. This layer is diffeult to identify; near volcanic islands it appears that it can be associated with lavas, but its existence in all areas makes it doubtful whether this interpretation can be true over all the sea floor. 'The velocity in it is such as might be expected for consolidated sedimentary rocks and it is possible that time and pressure have produced the necessary cementation or compaction of the deep sea sediments to produce this layer. 'The layer below this has a compressional wave velocity of $6.7 \mathrm{~km}$. $/ \mathrm{sec}$. and is usually supposed to represent basaltic rocks. Its thickness varies with location but in the deeper water it is approximately $4 \mathrm{~km}$. thick and overlies the mantle rocks, which have a compressional wave velocity of $8.1 \mathrm{~km}$./ $/ \mathrm{sec}$, This velocity is very close to that found at the Mohorovičic discontinuity at a depth of about $30 \mathrm{~km}$. under the continents.

In the north-east Atlantic, seismic refraction shooting observations during the past years have been made at more than thirty different positions and with a few exceptions these results conform with those obtained elsewhere. The first exception exists in the relatively shallow northern area mentioned earlier, where the thickness of the unconsolidated sediments is considerably greater than elsewhere, being in the neighbourhood of $2 \mathrm{~km}$. 'This thickening is possibly associated with the erosion products of the Pleistocene glaciation. The second exception is on the three seamounts and in the shallower water near the Azores, where there appears to be an additional layer, with compressional wave velocity about $3.8 \mathrm{~km}$./sec., between the unconsolidated sediments and the layer usually lying below, which has a velocity in the eastern Atlantic between approx. imately 4.5 and $5.4 \mathrm{~km}$./sec. This layer with velocity $3.8 \mathrm{~km}$./sec. can with fair certainty be associated with volcanic lavas.

In the recent expedition a series of observations was made at increasing distances from the Azores, and these showed that apart from the changes in water depth, and a thickening of the unconsolidated sedimentary layer in the shallower water, the structure was similar to that found elsewhere. In these measurements the method did not allow the depth to the layer with velocity $8.1 \mathrm{~km} . / \mathrm{sec}$. to be determined.

From the seismic observations obtained on the recent cruise of Discovery $I I$ and those obtained by Swallow and Hill on previous expeditions, it appears that the eastern Atlantic differs to no marked extent from the Pacific or the western Atlantic. Hill concluded his remarks by suggesting that those who favoured the hypothesis of continental drift in comparatively recent geological times would have difficulty in reconciling their conclusions with the crustal similarities between the Pacific and Atlantic Oceans.

Dr. M. N. Hill next described the nuclear spin magnetometer which had been constructed for towing astern of Discovery $I I$ during the expedition. 'This magnetometer relies upon the measurement of the precessional frequency of the spin axes of protons, the magnetic moment vectors of which have been displaced from alignment with the Earth's field and which are realigning themselves. The displacement of the protons in a water bottle is produced by a polarizing field not aligned with the Earth's field. This polarizing field is derived from a coil around the bottle; the coil is also used to detect the small 
alternating magnetic field (which is about $2,000 \mathrm{c} / \mathrm{s}$. in the latitude of Britain) produced by the precessing protons. The precessional frequency is directly proportional to the total field through the water sample. The advantages of the instrument are that calibration is unnecessary since the gyromagnetic ratio for the protons is known, and also that orientation of the bottle is not of importance provided its axis is not close to the direction of the Earth's field. This means that the object to be towed can be smaller than that of, for example, the towed fluxgate magnetometer. The body of the magnetometer used in the recent cruise was $5 \mathrm{ft}$. in length and $5 \mathrm{in}$. in outside diameter and was towed approximately $300 \mathrm{ft}$. astern. The electrical equipment necessary for the measurement of the precessional frequency was installed in the ship.

Sir Edward Bullard described the total force mag. netic measurements which were obtained with the nuclear spin magnetometer and with the fluxgate magnetometer on the recent cruise. One of the first interesting observations which resulted from these magnetic measurements was that which suggested that the Hercynian folding forming the Brittany Peninsula extended out to sea. A crossing of the line of its axis extended out over the continental shelf was obtained carly in the cruise and another on the return voyage to Plymouth, and both showed a considerable positive magnetic anomaly. Apart from this anomaly, the continental shelf and slope were magnetically smooth compared with the deeper water, where even in areas topographically flat considerable anomalies with a wave-length of the order of 12 miles were constantly observed. Even where there was some relief on the ocean floor it was not obvious if there was an association between these long wavelength anomalies and the topography. Superposed upon these long wave-length anomalies were those of about 2-miles wave-length which could sometimes be associated with topographic features.

Detailed magnetic surveys were made of the two seamounts where dan buoys were moored; although there appears to be some correlation between the depth and magnetic contours, it is not as good as would be expected if these seamounts, from a mag. netic point of view, consisted of lumps of magnetic material placed upon the sea floor.

Dr. J. C. Swallow described the deep water current measurement which had been obtained on the cruise. 'The method consists of loading aluminium alloy tubes so that at the surface they are slightly negatively buoyant. Since their compressibility is less than that of water, it can be arranged by suitable weighting that they reach a known depth where they possess neutral buoyancy. The tubes contain electrical sound-making devices which allow the floats to be followed for some days. Their position is determined relative to a fixed topographic feature of the sea floor. With the observations made on this cruise the current at 1,640 fathoms was found to be approximately $0.8 \mathrm{~cm} . / \mathrm{sec}$., or less than half $\mathrm{a}$ mile $\mathrm{a}$ day. The position of the observation was near the southeastern corner of the track of Discovery $I I$ and the depth of water about 2,800 fathoms. Dr. Swallow considers the magnitude of this bottom current to be so small that it may represent 'noise'; in order to obtain a more reliable estimate of the permanent current, observations would have to continue for a longer period than two days (see also Nature, 179, $1183 ; 1957)$.

Prof. W. F. Whittard spoke about a preliminary inspection he had made of the basalt boulders dredged from a seamount. These appeared at first sight to be weathered, since among other characteristics these rocks were exceptionally friable. It was difficult to understand how they could have got into this condition while resting on the floor of the deep ocean. Whittard also remarked that small pebbles dredged from the northern part of the Mid-Atlantic Ridge largely consisted of limestones and acidic igneous rocks. He expressed doubt if these could all have boen ice rafted.

Mr. A. R. Smith reviewed previous work on cosmic spherules derived from atmospheric dust collections and ocean sediments. He mentioned two recent theoretical indirect lines of investigation which suggest that there is an abundant supply of these spherules in space and that they can get through our atmosphere undamaged. He outlined an experimental programme which he is carrying out at Cambridge on the deep-sea cores obtained from the recent cruise. It is hoped that it will be possible to devise a positive method of identification of these spherules and to find out something about their density and composition, and their distribution in space.

In the discussion Dr. G. E. R. Deacon expressed satisfaction that Discovery $I I$ proved so versatile that the measurements described could be satisfactorily undertaken. It spoke well for the design of the ship that after nearly thirty years service she was still suited to modern techniques.

M. N. HILL

\section{THE UNIVERSITY OF READING}

\section{BY SIR JOHN WOLFENDEN, C.B.E. \\ Vice-Chancellor}

\begin{abstract}
HE University of Reading is on the move, literally as well as metaphorically. 'The new building in Whiteknights .Park which Her Majesty 'The Queen, accompanied by Prince Philip, recently opened is the first outward and visible sign of an imaginative and far-reaching plan of development. When this plan is completely realized the University of Reading will have a material equipment which will not easily be surpassed by any other University in Britain.

'The original home of the University Extension College was in the heart of the town of Reading.
\end{abstract}

It was a cluster of munieipal buildings (some of which have to-day become part of the Police Station) provided by the Borough Council to meet the needs of adult education as it was understood in the 1890's. The site was cramped, the buildings quickly became inadequate, and the atmosphere was inappropriate to the academic ambitions which the principal, Dr. W. M. Childs, and his colleagues properly cherished.

The energetic enthusiasm of Childs and the generous faith of Alfred Palmer made an irresistible combination. Between them they brought it about 